\title{
Study of the Efficacy of Stimulation Physiotherapy in the Management of Severe Acute Malnutrition in Children Aged 6-59 Months in Bamako, Mali
}

\author{
Maty Diagne Camara ${ }^{1, *}$, Cheikh Tacko Diop ${ }^{3}$, Oumar Bassoum ${ }^{2}$, Jean Augustin Diégane Tine², \\ Mohamed Ibrahim Mahmoud ${ }^{4}$, Mamadou Makhtar Mbacké Leye ${ }^{2}$, Mayacine Ndiongue ${ }^{2}$, \\ Kadim Niang ${ }^{2}$, Adama Faye ${ }^{2}$ \\ ${ }^{1}$ Faculty of Medicine, Pharmacy and Dentistry, Institute of Health and Development, Dakar, Senegal \\ ${ }^{2}$ Faculty of Medicine, Pharmacy and Dentistry, Service of Preventive Medicine and Public Health, Dakar, Senegal \\ ${ }^{3}$ Department of Community Health, Bambey University, Diourbel, Senegal \\ ${ }^{4}$ Direction of Nutrition, Ministry of Health, Bamako, Mali
}

Email address:

matydiagnecamara@gmail.com (M. D. Camara), matydiagne@yahoo.com (M. D. Camara)

${ }^{*}$ Corresponding author

\section{To cite this article:}

Maty Diagne Camara, Cheikh Tacko Diop, Oumar Bassoum, Jean Augustin Diégane Tine, Mohamed Ibrahim Mahmoud, Mamadou Makhtar Mbacké Leye, Mayacine Ndiongue, Kadim Niang, Adama Faye. Study of the Efficacy of Stimulation Physiotherapy in the Management of Severe Acute Malnutrition in Children Aged 6-59 Months in Bamako, Mali. American Journal of Pediatrics.

Vol. 6, No. 1, 2020, pp. 12-21. doi: 10.11648/j.ajp.20200601.12

Received: January 7, 2020; Accepted: January 21, 2020; Published: January 31, 2020

\begin{abstract}
The main objective of this study is to analyse the effects of stimulation kinesitherapy on psychomotor and cognitive development in these children followed by Severe Acute Malnutrition, aged 6 months to 59 months in the intensive nutritional educational recovery units. Prospective cohort study with 2 groups: one group subjected to stimulation Kinesitherapy and the other group without stimulation Kinesitherapy in six INERU in the District of Bamako. The population is represented by the children followed for Severe Acute Malnutrition, aged 6 months to 59 months in 6 of the 8 Bamako intensive nutritional educational recovery units of the "Strengthening Project intensive nutritional educational recovery units". The sampling is exhaustive, all children, aged 6 to 59 months, admitted to phase 2 of nutritional recovery between April 1, 2014 and July $15,2017$. The data collected includes socio-demographic, medical, psychomotor and anthropometric characteristics and physiotherapy sessions. Child development was measured using a child development assessment grid. An age-specific child development score was calculated. A bivariate analysis and a logistic regression were performed. The analysis covered 126 subjects in the group with kinesitherapy and 131 subjects in the group without Kinesitherapy. The psychomotor development score, weight/height ratio and developmental delay of the children after treatment were significantly improved in the group with stimulation Kinesitherapy compared to the group without stimulation Kinesitherapy $(\mathrm{p}<0.001)$. The children in the group without stimulation Kinesitherapy had 20.59 times more risk $(\mathrm{OR}=20.59 \mathrm{CI} 6.05$; 70.09) of having a developmental delay on Day 35 compared to the group with stimulation Kinesitherapy, after adjusting for age, developmental delay on Day 1, and the number of psychosocial stimulation sessions. Children with developmental delay on Day 1 were 4.16 times more likely (OR=4.16 CI 1.34; 12.90) to have a developmental delay on Day 35 compared to children without developmental delay on Day 1, after adjusting for age, physical stimulation therapy, and the number of psychosocial stimulation sessions. The anthropometric and psychomotor characteristics of the children after treatment were better in the Stimulation Kinesitherapy group, hence the need to reinforce stimulation and stimulation activities in the management of malnutrition in children aged 6-59 months.
\end{abstract}

Keywords: Malnutrition, Stimulation Kinesitherapy, Bamako

\section{Introduction}

Nutrition is increasingly recognized as a basic pillar for the social and economic development of communities and a country. Efforts to reduce malnutrition and mortality among infants and young children are essential to help achieve the 
Sustainable Development Goals (SDGs) [1].

Malnutrition is a global public health problem. The 2012 World Nutrition Report showed that although the prevalence of stunting has slowly declined globally, it affects at least 165 million children under 5 years of age in 2011 worldwide and at least 52 million of them are wasted or acutely malnourished [2]. This malnutrition leads to wasting and stunting, often associated with motor, mental and behavioural developmental delays, which can consolidate over time, or lead to irreversible disabilities if left untreated, but also to mental retardation and even cretinism in certain deficiencies. [3]

The 2015 World Nutrition Report showed that in developing countries, malnutrition remains a major health problem and is still the largest contributor to child mortality, accounting for $15 \%$ of the global burden of neonatal and child mortality. In 2015, the number of deaths of children under 5 years of age in the world was estimated at 5.9 million, $45 \%$ of which were attributable to malnutrition [4].

Malnutrition, especially in early childhood, affects vital functions, especially cognitive functions, and increases the risk of infection and mortality. It contributes to a significant extent to the entrenchment of poverty through obstacles linked to a low capacity for learning and production. Moreover, it is estimated that more than one third of deaths of children under five are directly or indirectly attributable to malnutrition. The risk of mortality due to acute malnutrition is 4 to 9 times higher than for healthy children [5]. Much research has shown that the survival rate of malnourished children during food crises depends not only on the availability of appropriate therapeutic foods, but also on the emotional and physical stimulation available to both the child and the caregiver (usually the mother). Thus it has also been shown that the combined use of emergency nutrition and emotional stimulation techniques contribute to lower malnutrition rates, higher child survival rates, and faster recovery from malnutrition [6].

The combination of malnutrition and lack of psychosocial stimulation is particularly harmful to children. Improving both nutritional status and stimulation have an impact on child survival, development and recovery. Therefore, nutritional and psychosocial interventions must be integrated. One third of children under 5 in developing countries are stunted [7] and several analyses show the strong correlation between stunting and cognitive deficiencies [8], even if the economic variables are positive. In addition to cognitive and educational delays in these children, emotional deficits have often been recorded as well as apathy, insecure attachment and lack of ability to engage in play and exploration activities. As children grow older, these delays manifest themselves as behavioral problems, attention deficits, and inability to establish appropriate social relationships [9].

The association between nutritional status and the achievement of a child's developmental potential is confirmed by the combination of emotional and nutritional recovery interventions. Cognitive, motor, and resulting social-emotional development of the child is greatly enhanced [10], with reduced recovery times, progressive elimination of maternal and childhood depression, and greatly reduced morbidity and relapse rates.

The motor care of children suffering from severe acute malnutrition is part of a field of Kinesitherapy that is no longer to be questioned. Adapted to the different phases of Severe acute malnutrition management, physiotherapy should prevent the appearance of sequelae in the musculo-articular apparatus (muscle retraction, joint limitation) and allow motor stimulation through the child's standard motor development sequences.

The World Health Organization recommendations on physical activities to be developed in the care of children with severe acute malnutrition include simple activities to be carried out by parents and health workers without prior training in physiotherapy. Within the framework of physiotherapy treatment for motor retardation, the practitioner will try to stimulate the child to perform an activity but, above all, his gestures will help guide the patient's movement. It is this facilitation phase which is the key to the treatment of motor retardation from a physiotherapic point of view.

Physiotherapy acts on the child's motor development patterns and promotes the return to correct movement by using certain facilitating actions. Once the child starts to recover appetite, it is considered to be in a phase of nutritional recovery, (transition phase). From this stage, activities to stimulate motor development can begin [11].

Stimulation physiotherapy aims at:

(a) To maintain the motor and articular capacity of the child, especially during the initial phase of the treatment of severe acute malnutrition,

(b) To stimulate the child in the realization of the sequences of motor development according to his age,

(c) To facilitate the movements of the child by an adapted guidance,

(d) To limit the delay of development consecutive to malnutrition,

(d) To prevent the after-effects consecutive to a delay of psychomotor development,

(f) To teach the mother or the person accompanying her the simple gestures of stimulation of the child.

Thus, the aim of this study is to evaluate the effect of stimulation physiotherapy on severely malnourished children aged between 6 and 59 months in Mali (Bamako) in order to better control and monitor the problem of malnutrition in children in developing countries in general, and in Mali in particular.

\section{Framework of the Study}

The study took place in the District of Bamako which extends from West to East over $22 \mathrm{~km}$ and from North to South over $12 \mathrm{~km}$, covering an area of $267 \mathrm{~km}^{2}$. In 2009, it had a population of $1,809,106$ and continues to attract a rural population in search of work. Women represent $49.8 \%$ of the population [12]. Children under the age of five years account for $16.8 \%$ of the population or 303,930 children [13]. 
The District of Bamako is divided into six communes. The health system has three levels of care: the central level, the intermediate level and the operational level which has 2 levels. The first level and first level of care offers the Minimum Activity Package in the Community Health Centers (699 in number). The second level or second level of health care utilization is constituted by the circle reference health centers, 59 in number.

The study was carried out in the health centers where Handicap International implemented the project. The study was carried out in the health centers where Handicap International has implemented the project: "Project to strengthen Intensive Nutritional Recovery Units by implementing early stimulation activities". The study took place in six intensive nutritional educational recovery units in the district of Bamako:

(a) Three reference sites: the intensive nutritional educational recovery units of the University Hospital Center Gabriel Toure, the intensive nutritional educational recovery units of the district reference health centers of Commune III, the intensive nutritional educational recovery units of the district reference health center of Commune VI.

(b) Three control sites: the intensive nutritional educational recovery units of the district reference health centers of Commune I, the intensive nutritional educational recovery units of the district reference health centers of Commune V, and the intensive nutritional educational recovery units of the district reference health centers of Commune IV.

\section{Method}

\subsection{Type of Study}

This is a prospective cohort study with 2 groups: one group subjected to stimulation physiotherapy and the other group without stimulation physiotherapy.

\subsection{Study Period}

The study took place from April 1 to July 15, 2017.

\subsection{Study Population}

The children, followed for MAS, aged between 6 and 59 months at the date of their care in phase 2 of nutritional recovery and cared for in 6 of the 8 Bamako intensive nutritional educational recovery units of the "Project for the reinforcement of intensive nutritional educational recovery units".

\subsection{Sampling Method}

All children, aged 6 months to 5 years, admitted to phase 2 nutritional recovery between April 1, 2017 and July 15, 2017 in the 6 study sites. Children with incomplete records (e.g., no final developmental assessment at five weeks), or those who had received too few sessions of physical stimulation therapy (less than five sessions) were not included in the study.

Sampling method: exhaustive sampling of all children admitted to the intensive nutritional educational recovery units concerned during the period in the 6 study sites.

Selection of case $\&$ control health centers: out of the 6 intensive nutritional educational recovery units selected out of 8 , three were used for the recruitment of the group treated with stimulation physiotherapy (intensive nutritional educational recovery units University Hospital Center Gabriel Toure, Commune III, Commune VI). The three others were used to select the children of the control group (intensive nutritional educational recovery units Commune I, Commune IV, Commune V). This selection of the intensive nutritional educational recovery units was made on the basis of the number of intensive nutritional educational recovery units patients and the possibility of setting up stimulation physiotherapy activities.

Sample size: For the study period under consideration, a minimum of one hundred (100) children in each group was expected. At the end of data collection, 125 children in the group with Stimulation Kinesitherapy and 139 children in the group without Stimulation Kinesitherapy were included.

\subsection{Data Collection}

Data collection was carried out in the health centers on 1 April 2014 and 15 July 2017:

(1) Socio-demographic characteristics of the child;

(2) Repeated anthropometric and medical measurements (at day 1 and day 35) made and reported by the doctor;

(3) Child's personal, medical and surgical history, and current pathologies, as informed by the doctor;

(4) Data on the child's psychomotor, cognitive, and social development: a grid for assessing the child's psychomotor, cognitive, and social development, to be completed at day 1 and day 35 by the physician, was used. This evaluation grid was based on a specific evaluation scale adapted to the context of this study, inspired by other existing scales already used in other places [14]. It was inserted into the child's data collection form and assessed several areas of child development: gross motor, language, fine motor, and comprehension. Based on the results of this assessment, an age-specific child development score was calculated on day 1 (initial situation) and day 35 (final situation).

(5) Psychosocial stimulation follow-up sheet, to be filled in at each session by the health worker who is conducting the session.

(6) Stimulation physiotherapy follow-up form, to be filled in at each session by the physiotherapist doing the session.

(7) Definition of the variables:

a. Developmental Delay of the children: it is the difference between the actual age and the developmental age. Developmental age: it is the highest age for which the child has passed all the tests [11].

b. Development Score of children: the ratio between the number of tests passed and the number of tests submitted (Development Score day 1=number of tests passed on day $1 /$ number of tests submitted on 
day 1; Development Score day 35=number of tests passed on day 35 / number of tests submitted on day 35).

c. Evolution of development scores: the difference between the development scores on day 35 and day 1. The calculation of the development score is done by annotating each test passed by "yes" which counts 1 point and each test failed by "no" which counts zero points. For each child, add up the "yeses" and divide the sum of the points obtained by the number of tests submitted to the child (i.e., the number of tests the child was given [11].

d. Evolution of the Weight for Height index: it is the Weight for Height index day 1 and day 35).

e. Number of days of hospitalization in the intensive nutritional educational recovery units: this is the difference between the date of arrival in the intensive nutritional educational recovery units and the date of discharge from the intensive nutritional educational recovery units.

(8) Investigator training

The medical evaluators (six doctors) and physiotherapists received special training on the use of the data collection tools from 04 to 11 March 2017. This training made it possible to: remind them about the normal and pathological development of children up to 5 years old; present the development evaluation grid; show how to use this grid in intensive nutritional educational recovery units children.

\subsection{Analysis}

Univariate analysis: to describe the qualitative and quantitative variables of socio-demographic characteristics with the calculation of frequencies and averages.

Bivariate analysis: allowed comparison of proportions and averages with use.

Multivariate analysis: we performed a logistic regression whose choice was based on the nature of the dependent variable which was developmental delay, which was a qualitative and dichotomous variable. It allowed us to determine the variables that are directly related to developmental delay.

Chi-square tests and the Fischer's exact test were used according to their conditions of application to compare the proportions. For cases where the distribution was not normal, the non-parametric Wilcoxon (Mann-Whitney) test was used. A matching analysis (day 35 vs. day 1) in each group of children was done using the signrank test (matched-series Wilcoxon). The tests were performed with a significance level of $5 \%$.

\section{Results}

In total the sample consisted of 125 children in the group with Stimulation Kinesitherapy and 139 children in the group without Stimulation Kinesitherapy.

\subsection{Socio-demographic Characteristics of the Two Groups at Day 1}

The sample of children in the two groups are identical in terms of socio-demographic characteristics $(p>0.05)$. (Table 1$)$.

Table 1. Socio-demographic characteristics of the two groups at day 1.

\begin{tabular}{|c|c|c|c|c|c|c|c|}
\hline \multirow{2}{*}{$\begin{array}{l}\text { Socio-demographic characteristics } \\
\text { Age }\end{array}$} & \multicolumn{2}{|c|}{$\begin{array}{l}\text { Group with Stimulation } \\
\text { Kinesitherapy }\end{array}$} & \multicolumn{2}{|c|}{$\begin{array}{l}\text { Group without Stimulation } \\
\text { Kinesitherapy }\end{array}$} & \multicolumn{2}{|l|}{ Total } & \multirow[t]{2}{*}{ P. Value } \\
\hline & & & & & & & \\
\hline Median Age & 13 & & 14 & & 13 & & \\
\hline 6 months- 11 months & 48 & 36,64 & 53 & 38,1 & 101 & 37,4 & 0.67 \\
\hline 12 months $-<24$ months & 61 & 46,56 & 68 & 38,1 & 129 & 47,78 & \\
\hline 24 months - 62 months & 22 & 16,79 & 18 & 12,95 & 40 & 14,81 & \\
\hline \multicolumn{8}{|l|}{ Sex } \\
\hline Female & 67 & 51,15 & 69 & 49,6 & 136 & 50,37 & 0,81 \\
\hline \multicolumn{8}{|l|}{ Place of residence } \\
\hline Bamako & 104 & 79 & 109 & 78 & 213 & 79 & \\
\hline Outside Bamako & 27 & 21 & 30 & 22 & 57 & 21 & \\
\hline \multicolumn{8}{|l|}{ Mother's education level } \\
\hline Education/Literacy & 42 & 33,3 & 44 & 34,9 & 86 & 34,1 & \multirow[b]{2}{*}{0,23} \\
\hline Not attending school & 82 & 65,1 & 74 & 58,7 & 156 & 61,9 & \\
\hline \multicolumn{8}{|l|}{ Father's education Level } \\
\hline Education/Literacy & 52 & $42,6 \%$ & 56 & $47,1 \%$ & 108 & $44,8 \%$ & \multirow{3}{*}{0,28} \\
\hline Not attending school & 67 & $54,9 \%$ & 54 & $45,4 \%$ & 121 & $50,2 \%$ & \\
\hline Koranic & 3 & $2,5 \%$ & 9 & $7,5 \%$ & 12 & $5,0 \%$ & \\
\hline
\end{tabular}

\subsection{Anthropometric and Developmental Delay Characteristics at Day 1}

Concerning the Weight-for-height index no statistically significant difference $(\mathrm{p}>0.05)$ was revealed at day 1 in the two groups. However, children in the group with physiotherapy had a greater developmental delay $(8.98+/-$ 9.12) than children in the control group (5.02+/-6.56) $(<0.001)$. Also the children in the group with physiotherapy had a lower developmental score $(0.57+/-0.25)$ than the 
children in the control group $(0.74+/-0.24)$, which is in line $\quad(p<0.001)$ (see Table 2). with the previous results concerning developmental delay.

Table 2. Weight-for-height index, developmental delay, and developmental score of both groups at Day 1.

\begin{tabular}{llll}
\hline Characteristics of the two groups & $\begin{array}{l}\text { Group with Stimulation } \\
\text { Kinesitherapy }(\mathbf{n}=\mathbf{1 3 1})\end{array}$ & $\begin{array}{l}\text { Group without Stimulation } \\
\text { Kinesitherapy }(\mathbf{n}=\mathbf{1 3 9})\end{array}$ & Total $(\mathbf{n}=\mathbf{2 7 0})$ \\
\hline Weight-for-height index $<-3$ z-score & & & \\
25th percentile & $-4,813$ & $-4,384$ & 0,078 \\
Median & $-3,796$ & $-3,706$ & 0,086 \\
75th percentile & $-3,127$ & $-3,089$ & 0,093 \\
Minimum & $-6,726$ & $-7,079$ & 0,1 \\
Maximum & 0,923 & -0.562 & 0,128 \\
Mean +/- SD & $-3,820+/-1,469$ & $-3,797+/-1,1617$ & $0,086+/-0,013$ \\
Developmental Delay Day 1 & & & \\
25th percentile & 3 & 0 & 1 \\
Median & 6 & 2.5 & 4 \\
75th percentile & 12 & 8 & 10 \\
Minimum & -2 & -1 & -2 \\
Maximum & 47 & 32 & 47 \\
Mean+/- SD & $8.98+/-9,12$ & $5.02+/-6,56$ & $6,92+/-8,11$ \\
Development Score & & & $0,46^{*}$ \\
25th percentile & 0,41 & 0,61 & 0,52 \\
Median & 0,61 & 0,78 & 0,69 \\
75th percentile & 0,76 & 0,94 & 0,86 \\
Minimum & 0 & 0,01 & 0 \\
Maximum & 1 & 1 & 1 \\
Mean+/- SD & $0,57+/-0,25$ & $0,74+/-0,24$ & $0,66+/-0,26$ \\
\hline
\end{tabular}

* Wilcoxon/Mann-Whitney test significant $(<0.05)$.

\subsection{Development Score by Area of Development on Day 1}

The development score was broken down into 4 domains: gross motor, language, fine motor and comprehension. Comparisons by domain are presented in Table 3 .

On day 1, the score for development, gross motor, language, fine motor (grasping) and comprehension appeared significantly higher in the group without Stimulation Kinesitherapy than in the group with Stimulation Kinesitherapy $(\mathrm{p}<0.001)$.
The sample of case children who received Stimulation Kinesitherapy and the sample of control children who did not receive any Stimulation Kinesitherapy, therefore, show a different initial situation at $\mathrm{J} 1$ for language, grasping and comprehension; the children in the group with Stimulation Kinesitherapy have a lower developmental score than the children in the control group, which is in line with the previous findings for developmental delay. (Table 3).

Table 3. Development Score by Area of Development on day 1.

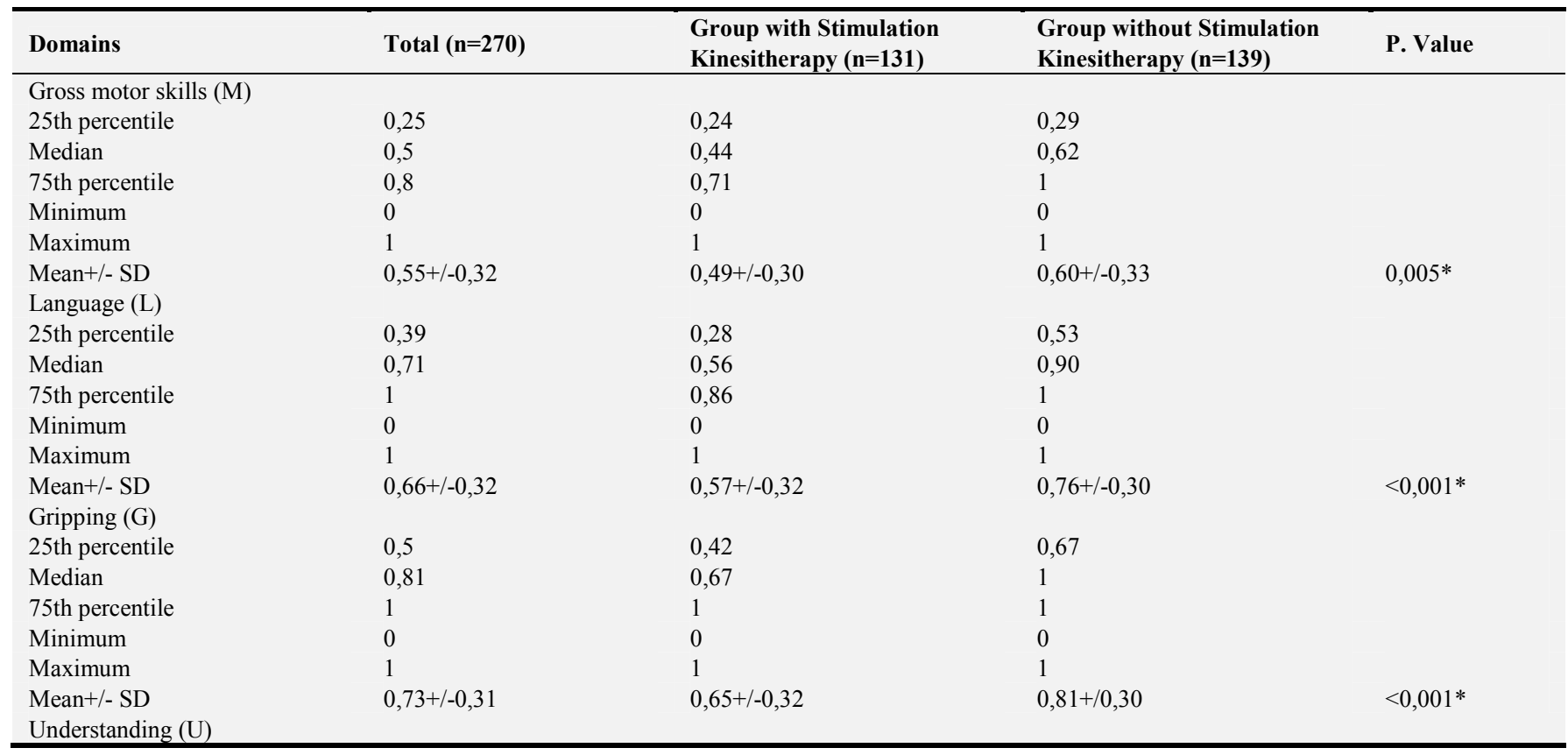




\begin{tabular}{|c|c|c|c|c|}
\hline Domains & Total $(n=270)$ & $\begin{array}{l}\text { Group with Stimulation } \\
\text { Kinesitherapy }(n=131)\end{array}$ & $\begin{array}{l}\text { Group without Stimulation } \\
\text { Kinesitherapy }(n=139)\end{array}$ & P. Value \\
\hline 25th percentile & 0,54 & 0,39 & 0,71 & \\
\hline Median & 0,79 & 0,67 & 1 & \\
\hline 75th percentile & 1 & 0,87 & 1 & \\
\hline Minimum & 0 & 0 & 0,03 & \\
\hline Maximum & 1 & 1 & 1 & \\
\hline Mean+/- SD & $0,73+/-0,30$ & $0,62+/-0,30$ & $0,83+/-0,24$ & $<0,001 *$ \\
\hline
\end{tabular}

* Wilcoxon/Mann-Whitney test significant $(<0.05)$.

\subsection{Medical Characteristics}

On day 1, medical characteristics were comparable between the group with Stimulation Kinesitherapy and the group without Stimulation Kinesitherapy, except for medical history $(\mathrm{p}<0.001)$ and current neurological pathology $(\mathrm{p}=0.02)$. These were significantly higher in the group with Stimulation Kinesitherapy than in the group without Stimulation Kinesitherapy. (See Table 4).

Table 4. Medical characteristics between the two groups on day 1.

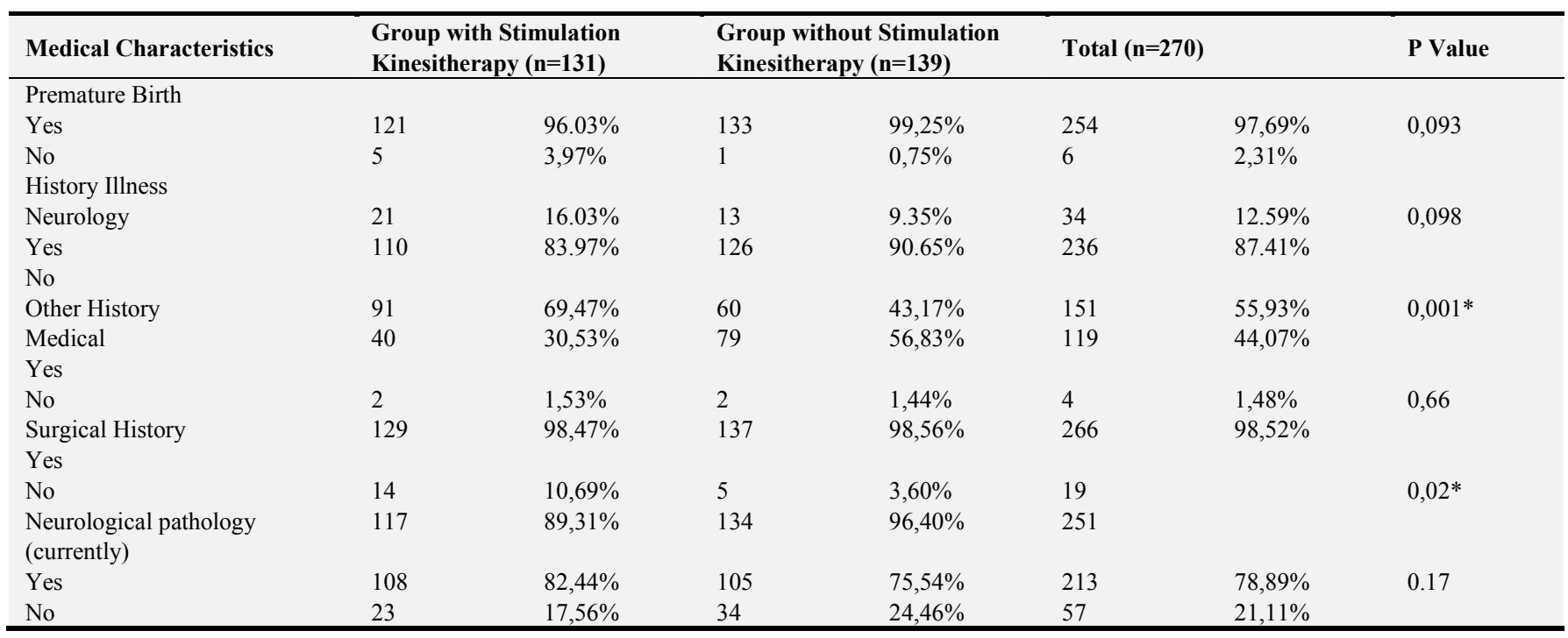

\subsection{Effect of Physiotherapy on Intensive Nutritional Educational Recovery Units Hospitalization Days}

At day 35, the difference in the number of intensive nutritional educational recovery units days was significant $(p<0.001)$ between the two groups. Children in the group with Stimulation Kinesitherapy stayed in hospital longer than children in the group without Stimulation Kinesitherapy (mean 17.94+/- 9.96 days versus $9.63+/-6.87$ days, respectively). (See Table).

Table 5. Description of the number of days of hospitalization in the intensive nutritional educational recovery units.

\begin{tabular}{lll}
\hline $\begin{array}{l}\text { Intensive nutritional educational } \\
\text { recovery units hospitalization days }\end{array}$ & $\begin{array}{l}\text { Group with Stimulation Kinesitherapy } \\
(\mathbf{n = 1 2 2})\end{array}$ & $\begin{array}{l}\text { Group without Stimulation } \\
\text { Kinesitherapy (n=134) }\end{array}$ \\
\hline Minimum & 2 & 1 \\
Maximum & 51 & 50 \\
Mean & 17,94 & 9,63 \\
Median & 16 & 7 \\
SD & 9,97 & 6,87 \\
\hline
\end{tabular}

\subsection{Effect of Physiotherapy on the Evolution of the Weight for Height Index, Developmental Delay and Development Score}

At day $35,25 \%$ of the children in the stimulation physiotherapy group had a weight/height ratio of less than $1.9870 \mathrm{z}$. score compared to $-3.940 \mathrm{z}$. score for those without physiotherapy. The weight/height ratio of the children was significantly higher in the group with Stimulation Kinesitherapy compared to the group without Stimulation Kinesitherapy.

The median developmental delay of the children with Stimulation Kinesitherapy appeared significantly lower than that of the children in the group without Stimulation Kinesitherapy $(p<0.001)$ at D35.

The developmental score at day 35 of the children with Stimulation Kinesitherapy was significantly higher in the 
group than in the group without Stimulation Kinesitherapy $\quad(p<0.001)$. (See Table 6).

Table 6. Weight-for-height index, developmental delay and development score at day 35.

\begin{tabular}{lll}
\hline & $\begin{array}{l}\text { Group with Stimulation } \\
\text { Kinesitherapy (n=126) }\end{array}$ & $\begin{array}{l}\text { Group without Stimulation } \\
\text { Kinesitherapy (n=139) }\end{array}$ \\
\hline Height-Weight Index (P (T)<-3 z-score) & & \\
25th percentile & $-1,9870$ & $-3,940$ \\
Median & -0.7010 & -3.240 \\
75th percentile & 0.8295 & -2.254 \\
Minimum & -5.0480 & -7.281 \\
Maximum & 5.2880 & 3.606 \\
Mean +/- SD & $-0.4801+/-2,23$ & $-3.105+/-1,44$ \\
Developmental delay (months) & & 2 \\
25th percentile & 0 & 4 \\
Median & 2 & 8 \\
75th percentile & 5 & $-1,5$ \\
Minimum & -3 & 38 \\
Maximum & 46 & $6,032+/-6,305$ \\
Mean +/- SD & $4.928+/-8.484$ & \\
Development Score at Day 35 & & 0,684 \\
25th percentile & 0,7 & 0,8 \\
Median & 0,889 & 0.884 \\
75th percentile & 1 & 0,008 \\
Minimum & 0 & 1 \\
Maximum & 1 & $0,750+/-0,194$ \\
Mean +/- SD & $0,815+/-0,213$ & \\
\hline
\end{tabular}

\subsection{Evolution of Developmental Delay of Severe Acute Malnutrition Children Between Day 1 and Day 35}

It appears that the median of developmental delay decreases significantly in the groups with stimulation kinesitherapy, which is not the case in the group without stimulation kinesitherapy. $\mathrm{p}<0.001$ (signrank test day 35 vs. day 1 in the same group) (see figure 1).

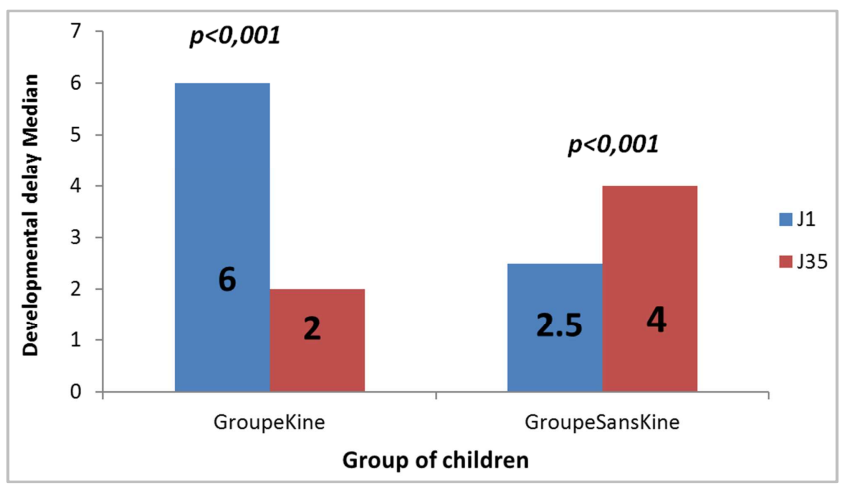

Figure 1. Developmental delay by group of children.

\subsection{Evolution of the Development Score}

Figure 2 above shows a slight evolution of the development score between day 1 and day 35 in the group without physiotherapy, whereas it increased significantly in the group with stimulation Kinesitherapy.

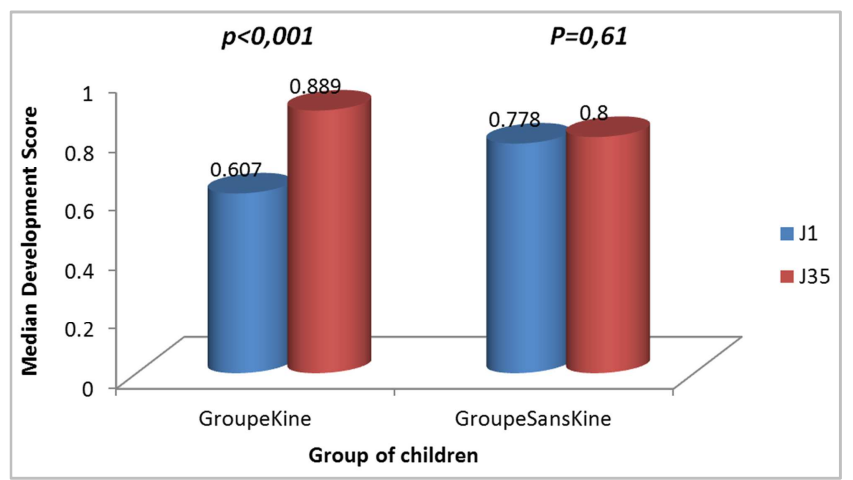

Figure 2. Scores de développement selon le groupe d'enfants.

\subsection{Evolution of the Development Score by Sector}

At day 35, the evolution of the development score for language, grasping, comprehension and motor skills was significantly higher $(\mathrm{p}<0.001)$ in the group with stimulation kinesitherapy than in the group without stimulation kinesitherapy. (see Table 7)

Table 7. Evolution of the development score by development sector on Day 35.

\begin{tabular}{lllll}
\hline & Total $(\mathbf{n}=\mathbf{2 6 2})$ & $\begin{array}{l}\text { Group with Stimulation } \\
\text { Kinesiotherapy }(\mathbf{n}=\mathbf{1 2 5})\end{array}$ & $\begin{array}{l}\text { Group without Stimulation } \\
\text { Kinesitherapy }(\mathbf{n}=\mathbf{1 3 7})\end{array}$ & P Value \\
\hline Gross motor skills $(\mathrm{M})$ & & & & $-0,77$ \\
Minimum & $-0,77$ & $-0,42$ & 0,38 & $p<0,001^{*}$ \\
Maximum & 0,92 & 0,92 & $-0,08+/-0,22$ & \\
Mean + - SD & $0,07+/-0,28$ & $0,24+/-0,26$ & \\
\hline
\end{tabular}




\begin{tabular}{llll}
\hline & Total (n=262) & $\begin{array}{l}\text { Group with Stimulation } \\
\text { Kinesiotherapy (n=125) }\end{array}$ & $\begin{array}{l}\text { Group without Stimulation } \\
\text { Kinesitherapy (n=137) }\end{array}$ \\
\hline 25th Percentile & $-0,08$ & 0,05 & $-0,2$ \\
Median & 0,03 & 0,22 & $-0,04$ \\
75th Percentile & 0,25 & 0,41 & 0,05 \\
Langage (L) & & & \\
Minimum & $-0,86$ & $-0,86$ & $-0,6$ \\
Maximum & 0,92 & 0,92 & 0,75 \\
Mean +/- SD & $0,12+/-.31$ & $0,24+/-0,34$ & $0,01+/-0,25$ \\
25th Percentile & 0 & 0 & $-0,088$ \\
Median & 0 & 0,238 & 0 \\
75th Percentile & 0,33 & 0,5 & 0,096 \\
Préhension (P) & & & \\
Minimum & $-0,71$ & $-0,71$ & $-0,57$ \\
Maximum & 1 & 1 & .95 \\
Mean +/- SD & $0,15+/-0,29$ & $0,24+/-0,33$ & $0,07+/-0,21$ \\
25th Percentile & 0 & 0 & 0 \\
Median & 0 & 0,2 & 0 \\
75th Percentile & 0,33 & 0,46 & 0,12 \\
Compréhension (C) & & & \\
Minimum & $-0,82$ & $-0,623$ & $-0,82$ \\
Maximum & 1 & 1 & .787 \\
Mean +/- SD & $0,13+/-0,29$ & $0,3+/-0,33$ & $0,03+/-0,21$ \\
25th Percentile & 0 & 0 & 0 \\
Median & 0 & 0,21 & 0 \\
75th Percentile & 0,29 & 0,45 & 1 \\
\hline
\end{tabular}

\subsection{Psychosocial Stimulation Sessions from Day 1 to Day 35}

At day 35, the number of psychosocial stimulation sessions was on average $9+/-5.2$ for the group with stimulation kinesiotherapy versus $3.13+/-3.8$ for the group without stimulation kinesiotherapy. The difference was significant between the two groups $(\mathrm{p}<0.001)$; the group with stimulation kinesitherapy received more psychosocial stimulation sessions than the group without stimulation kinesitherapy on day 35 .

Table 8. Number of psycho-social stimulation sessions in both groups.

\begin{tabular}{lll}
\hline $\begin{array}{l}\text { Number of psychosocial stimulation } \\
\text { sessions }\end{array}$ & $\begin{array}{l}\text { Group with Stimulation Kinesiotherapy } \\
(\mathbf{n = 1 3 1})\end{array}$ & $\begin{array}{l}\text { Group without Stimulation } \\
\text { Kinesitherapy (n=139) }\end{array}$ \\
\hline Minimum & 0 & 0 \\
Maximum & 24 & 12 \\
Mean & $9.489+/-5.180$ & $3.129+/-3.814$ \\
Median & 9 & 1 \\
\hline
\end{tabular}

\subsection{Multivariate Analysis}

Risk factors related to developmental delay day 35

In order to verify the factors related to the developmental delay at day 35 in the group of children having benefited from stimulation physiotherapy sessions, a logistic regression was carried out. The control variables selected were age, the number of psychosocial stimulation sessions and the developmental delay observed at day 1. (See table 8).

Table 9. Risk Factors for Delayed Development at day 35.

\begin{tabular}{llll}
\hline Risk Factors & OR & IC à 95\% & P \\
\hline Age & & & - \\
6-11 months & Réf & 0,$31 ; 1,32$ & 0,23 \\
$12-23$ months & 0,640 & 0,$84 ; 12,36$ & 0,09 \\
24 to 63 month & 3,23 & 0,$69 ; 2,09$ & 0,52 \\
Psychosocial stimulation sessions & 1.20 & 1,$34 ; 12,90$ & 0,013 \\
Development delay day 1 & 4,16 & 6,$05 ; 70,09$ & $<0.001$ \\
Lack of physical therapy & 20,59 & & \\
\hline
\end{tabular}

\section{Discussion}

The age group of children between 12 and 24 months was the most represented at $47.78 \%$. This result is close to that of
S. Diarra in Mali [15], Testa et al. in Benin [16] and Arama in Koutiala, Mali [17], according to which the age group most affected is between 12 and 24 months with $52.04 \%$ of cases.

The majority of the parents of the children $(61.90 \%$ of 
mothers and $50.21 \%$ of fathers) surveyed were out of school, as attested by the study by S. Diarra [15], who stated that the higher the mother's level of education, the lower the prevalence of stunting and underweight. Illiteracy leads to nutritional imbalance and even malnutrition [16].

The children stayed in hospital more in the group with stimulation kinesiotherapy than in the group without stimulation kinesiotherapy. This could be explained by the fact that at the other sites which were reference health centers, hospitalization could not exceed one week contrary to the Gabriel Toure hospital where the greatest number of children (75\%) severe acute malnutrition with stimulation physiotherapy was recruited. The children's stay was shorter than the 30 days observed by Sall et al [18] in 1999 in Dakar, Senegal and 24 days by Sonde [19] in 2009 in Tenghin, Burkina Faso. On the other hand, it was longer than the 14.8 and 15 days observed respectively by Van Roosmalen et al [20] in Tanzania in 1987 and by Sall et al [21] in 2000 in Kaolack in Senegal.

Between day 1 and day 35, the number of psychosocial stimulation sessions was higher in the group with stimulation kinesiotherapy than in the group without stimulation kinesiotherapy. This could be explained by the fact that, on the one hand, the health workers in the control sites did not always indicate this part on the data collection form, and on the other hand, the physiotherapy activities motivated the health workers in charge of psychosocial stimulation so that, at each physiotherapy session, the health workers also stimulated the children.

At admission, the children in the group without stimulation kinesiotherapy had a better developmental score than those in the group with stimulation kinesiotherapy, but at discharge the children's developmental score was significantly higher in the group with stimulation kinesiotherapy than in the control group after care.

The developmental delay of the children was significantly lower in the group with stimulation kinesiotherapy compared to the group without stimulation kinesiotherapy. This can be explained by the stimulation kinesiotherapy treatment because we found that the children in the stimulation kinesiotherapy group had a greater developmental delay at admission than those without stimulation kinesiotherapy, but after being treated by the stimulation kinesiotherapy sessions, the situation was reversed: the developmental delay became low in the group with stimulation kinesiotherapy. These results would support the thesis of the intervention of Handicap in North Kivu (Democratic Republic of Congo) in 2008 and in South Sudan in 2012 [11].

At admission, the weight-for-height index was identical in both groups, but by the end of the treatment the weight-forheight index of the severe acute malnutrition children in the group with stimulation kinesiotherapy was significantly better than in the group without stimulation kinesiotherapy.

Stimulation kinesiotherapy would have a positive effect on the developmental variables used in this study. Indeed, children in the group without stimulation kinesiotherapy had 20 times the risk of having a developmental delay on day 35 compared to the group with stimulation kinesiotherapy, after adjusting for age, developmental delay on day 1, and the number of psychosocial stimulation sessions. These results support the World Health Organization thesis [22] and the recommendations of the severe acute malnutrition management protocol [23] on the importance of stimulation activities for malnourished children.

The children in the group without physiotherapy were 20.59 times more likely $(\mathrm{OR}=20.59 \mathrm{CI} 6.05 ; 70.09)$ to have a developmental delay on day 35 compared to the group with physiotherapy, after adjusting for age, developmental delay on day 1, and the number of psychosocial stimulation sessions.

Children with developmental delay on day 1 were 4.16 times more likely $(\mathrm{OR}=4.16$ CI $1.34 ; 12.90)$ to be developmentally delayed on day 35 compared to children without developmental delay on day 1 , after adjusting for age, physical stimulation therapy, and the number of psychosocial stimulation sessions.

\section{Conclusion}

This study allowed us to study the effectiveness of stimulation physiotherapy in severe acute malnutrition children. The developmental score of the severe acute malnutrition severe acute malnutrition children in the group with stimulation kinesiotherapy was improved compared to the group without stimulation kinesiotherapy. The developmental delay of the severe acute malnutrition children in the group with stimulation kinesiotherapy was improved compared to the group without stimulation kinesiotherapy. The weight/height ratio of the severe acute malnutrition children in the group with stimulation kinesiotherapy was improved compared to the group without stimulation kinesiotherapy.

This first research was carried out on a limited sample. If the results show a positive effect of stimulation kinesiotherapy on the development of children suffering from severe acute malnutrition, a larger scale, even multicentre study would allow to confirm these results and to analyse in more detail the impact of this activity.

\section{References}

[1] ONU: Conférence de Rio +20 , Eliminer la pauvreté, c'est possible: Objectifs du millénaire pour le développement et l'après- 2015, Rio, Août 2014.

[2] UNICEF-OMS-Banque mondiale, Joint Child Malnutrition Estimates: Levels and Trends in Child Malnutrition, UNICEF, OMS, Banque mondiale, 2012; statistical table. Les chiffres concernent l'année 2011. http://www.who. int/nutgrowthdb/statistical_tables.pdf.

[3] Robert E Black, et al. 2013. Maternal and child undernutrition and overweight in low-income and middle-income countries. Lancet 2013/Published Online June 6, 2013 http://dx.doi.org/10.1016/ S0140-6736(13)60937-X. 
[4] Martin-Prével Yves (collab.). (2015). Rapport 2015 sur la nutrition mondiale: mesures et redevabilité en vue d'accélérer les progrès mondiaux en matière de nutrition et de développement durable. Washington: IFPRI, 190 p. (Global Nutrition Report). ISBN 978-0-89629-884-2.

[5] Black, Robert E., et al.: 'Maternal and Child Undernutrition: Global and regional exposures and health consequences', The Lancet, vol. 371 no. 9608, 19 January 2008, pp. 243-26.

[6] Grantham-McGregor S, Schofield W, and Harris L.: Effect of psychosocial stimulation on mental development of severely malnourished children: an interim report. Pediatrics. 1983; 72: 239-43.

[7] Unicef. The State of the World's Children 2005: children under threat. New York: Unicef, 2004.

[8] Walker SP, Chang SM, Powell CA, Grantham-McGregor SM. Effects of early childhood psychosocial stimulation and nutritional supplementation on cognition and education in growth-stunted Jamaican children: prospective cohort study. Lancet 2005; 366 (9499): 1804-7.

[9] Chang SM, Walker SP, Grantham-McGregor S, Powell CA. Early childhood stunting and later behaviour and school achievement. J Child Psychol Psychiatry 2002; 43 (6): 775-83, 21 .

[10] Pollitt E, Schurch B. Developmental pathways of the malnourished child. Results of a supplementation trial in Indonesia. Eur J Clin Nutr 2000; 54 (suppl 2): 2-113.).

[11] Handicap International: Approche kinésithérapique de la malnutrition aiguë sévère 2012, p 10.

[12] http://fr.wikipedia.org/wiki/Bamako, P1, consulté le 11/12/2014 à $10 \mathrm{~h} 54 \mathrm{mn}$.

[13] Ministère de la santé Mali, cellule de la planification et de la statistique, enquête démographique et de santé V (EDS V) 2012- 2013, p 22.

[14] Powell C, Baker-Henningham H, Walker S, Gernay J, Grantham-McGregor S, 1994. Feasibility of integrating early stimulation into primary care for undernourished Jamaican children: cluster randomised controlled trial. British Medical Journal, 329, p 89.
[15] DIARRA S. Les facteurs de risques de la malnutrition au mali, [Mémoire de Master 2 Santé Publique], Bamako 2014; p 46.

[16] Testa J, Sinnaeve O, Ibrahim Y, Ayibi V. Evaluation de la qualité du dépistage et de la prise en charge de la malnutrition infantile à Cotonou, Bénin. Med Trop 2008, p 45.

[17] ARAMA E: La malnutrition infanto-juvénile: aspects épidémiologiques et prise en charge dans le district sanitaire de Koutiala (mali), [Mémoire de Master 2 Santé Publique], ISPED Bordeaux 2009. P 54.

[18] SALL MG, DANKOKO B, BADIANE M, EHUA E et KUAKUWI N. Résultats d'un essai de réhabilitation nutritionnelle avec la spiruline a Dakar (A propos de 59 cas). Médecine d'Afrique Noire: 1999, 46 (3).

[19] Sonde I. Analyse de la prise en charge des enfants en malnutrition au centre de récupération nutritionnelle (CREN) de Tenghin [memoire: santé publique]. Louvain: Université Catholique de Louvain 2009, disponible sur $\mathrm{http} / / / w w w . m e m o i r e o n e l i n e . c o m . / 10 / 10 / 4055 / \mathrm{m}$ _Analyse-dela-prise-en-charge-denfants-en-malnutritionau-centre-derecuperation-nutritionnelle-0.html. Consulté le 6 juillet 2015 à $11 \mathrm{~h} 02 \mathrm{mn}$.

[20] VAN ROOSMALEN-WIEBENGA MW., KUSIN J. A., DE WITH C. Nutrition rehabilitation in hospital, a waste of time and money ? Evaluation of nutrition rehabilitation in a rural district hospital in southwest Tanzania. II. Long term results. J, Trop, Ped, 1987, 33, 24-8.

[21] SALL M. G., BADJI M. L., MARTIN S. L., KUAKUVI N. Récupération nutritionnelle en milieu hospitalier regional: Le cas de l'Hôpital Régional de Kaolack (Sénégal). Médecine d'Afrique Noire: 2000, 47 (12).

[22] Organisation Mondiale de la Santé: prise en charge communautaire de la malnutrition aiguë sévère 2007 disponible sur http://www.who.int/maternal_child_adolescent/documents/pdf s/severe_acute_malnutrition_fr.pd (Consulté le 06/07/2015).

[23] Ministère de la Santé du Mali: Protocole de Prise en Charge. 